\title{
Noise Induced Hearing Loss in Korea
}

\author{
KyooSang Kim \\ Department of Occupational and Environmental Medicine, Seoul Medical Center, Seoul, Korea
}

\author{
소음성 난청 \\ 김 규 상 \\ 서울의료원 직업환경의학과
}

\begin{abstract}
The noise has auditory effects such as hearing loss and tinnitus, and non-auditory physiological effects such as hypertension and ischemic heart disease. Also, the noise influences daily life psychosocially and behaviorally. In this paper, we described the situation of noise exposure and noise-induced hearing loss in South Korea industry, and investigated the health effects of noise. In addition, to reduce noise exposure in the workplace, we examined the environmental noise measurement, exposure limits, special medical examination for the early diagnosis of noise-induced hearing loss, and systematic programs for hearing conservation.
\end{abstract}

Key Words: Noise, Noise-induced hearing loss (NIHL), Prevention, Korea.

Received: February 12, 2016 / Accepted: March 10, 2016

Correspondence: KyooSang Kim, Department of Occupational and Environmental Medicine, Seoul Medical Center, 156 Sinnae-ro, Jungnang-gu, Seoul 02053 Korea

Tel: +82-2-2276-7755 / Fax: +82-2-2276-7438 / E-mail: kyoosang@daum.net

\section{INTRODUCTION}

소음은 ‘원하지 않는 소리' 또는 '정신적, 육체적으로 인체에 유해한 소리'로 우리나라의 소음진동관리법」 제2조에서는 "기 계·기구·시설, 그 밖의 물체의 사용 또는 공동주택 등 환경부 령으로 정하는 장소에서 사람의 활동으로 인하여 발생하는 강 한 소리”로 규정하고 있다. 소음은 인간이 듣기 싫어하는 소리 (횹)의 총칭으로 일반적으로 특히 큰 소리, 불쾌한 음색이나 충 격성의 음, 대화나 음악의 청취를 방해하는 소리, 생리적으로 장애를 일으키는 소리, 주의집중이나 작업을 방해하는 소리, 숙면이나 휴식을 방해하는 소리이다.

소음은 사업장 내의 생산라인과 건설 중장비, 발파소음 등 건설 현장에서의 작업자만이 아니라 자동차·기차·항공기 등 운송수단에 의한 교통 소음이나 전투기·사격장 등의 국방 관 련 소음원에 일반 지역주민이 노출되고 있다. 최근에는 외부에 서 발생되는 이동 발생원인 교통 소음만이 아니라, 공동주택과 사무실 실내 내부에서 발생되는 소음원인 바닥충격 소음, 세대 간 공기전달음, 급배수 설비 소음, 가전기기 소음과 사무실 공 조 소음 등 생활소음도 사회적 이슈가 되어 공동주택의 층간소
음에 대한 규정이 마련되었다.

세계보건기구는 인간의 감각기관으로 감지한다고 해서 '감각 공해'라 불리는 소음이 건강에 미치는 영향에 주목하고 있다. 세계적으로 소음으로 인해 청력장애를 호소하는 사람이 늘고 있다. 미국에서 9백만명이 $85 \mathrm{~dB}$ 이상 노출되며, 1000 만명이 $25 \mathrm{~dB}$ 이상의 소음성 난청, 그리고 유럽에서는 $28 \%$, 즉 근로자 의 $1 / 4$ 이상이 85 90 dB에 노출되고 있다. 전세계적으로 1 억 2 천만명에서 2 억5천만명이 청력손실로 추정되는데 15 번째의 주 요한 건강문제이다(Nelson et al., 2005). 성인에서 발생하는 청 력손실의 $16 \%$ 가 소음에 의해 기인한다고 보고하고 있다. 미국 의 제3차 국민건강영양조사(the Third National Health and Nutrition Examination Survey, NHANES III)에서 1988 1994년도의 6 19세 5,249명의 아동에 대한 청각학적 검사 결과 $12.5 \%$ (520만명 추정)의 소음성 청력역치 변동(noise-induced hearing threshold shifts, NITS)을 보고하고 있어 높은 수준의 소음에 노출되고 있음을 알 수 있다(Niskar et al., 2001).

이 글은 한국의 산업장의 소음 노출과 소음성 난청(noiseinduced hearing loss, NIHL)의 실태, 소음의 건강영향 및 소 음 예방 대책을 다루고자 한다. 


\section{STATUS OF NOISE EXPOSURE AND NIHL}

소음은 우리나라 제조업체 사업장 근로자의 주요한 노출 유 해요인이며 그로 인한 건강장애로서 많은 소음성 난청을 발생 시키고 있다.

청력에 영향을 미치고 일반적인 청력 건강감시를 수행하는 $85 \mathrm{~dB}(\mathrm{~A})$ 이상의 소음에 노출되는 주요 업종은 제조업 이외에 도 광업, 건설업 및 운수업 등 다양하다. 우리나라의 작업환경 측정 대상 유해인자 중 소음이 노출기준 초과사업장의 $90 \%$ 이 상을 차지하고 있다. 작업 환경 중 소음의 노출기준 초과율은 감소 추세에 있으나 유해인자 중 가장 높은 초과율을 보이고 있다. $100 \mathrm{~dB}(\mathrm{~A})$ 을 초과하는 건수는 $1.3 \%$ 존재하며, $80 \mathrm{~dB}(\mathrm{~A})$ 미만의 소음은 $11.1 \%$ 를 차지하고 있다(Jang \& Chung, 2007). 최근 연구에서 우리나라 대상 사업장 전체의 소음 노출 기준 초과율(소음 작업환경 측정 건수 대비 소음 노출 기준인 8시간 $90 \mathrm{~dB}(\mathrm{~A})$ 초과 건수 비율)은 $12.19 \%$, 소음 노출 수준은 8시간 가중 노출 평균값으로 $84.68 \mathrm{~dB}(\mathrm{~A})$, 중앙값으로는 83.91 $\mathrm{dB}(\mathrm{A})$, 초과 사업장[사업장별 소음 작업환경 측정 결과 8시간 노출량(TWA)이 측정 건수 중 하나 이상이라도 초과한 사업장 수]은 4,723개 사업장 $(26.3 \%)$, 측정 건수 중 초과한 건수가 $50 \%$ 이상의 초과율을 보인 사업장은 2,045개(11.4\%), 1/4 3/4 분위 값인 25 75\% 범위의 소음 수준은 81.51 87.90 dB(A)이 었다(Kim et al., 2010).

소음성 난청은 1991년 이후 특수건강진단에 의해 발견되는 직업성 질환 유소견자 중 가장 많은 비율을 차지하고 있다. 2014 년 특수건강진단은 56,873개소 사업장에서 근로자 1410,335 명 이 실시하고 그 중 소음 특수건강진단 대상자 609,339명 중 소음 성 난청 요관찰자 $(\mathrm{Cl})$ 는 126,300 명, 소음성 난청 유소견자(D1) 는 8,428 명이었다. 소음성 난청이 직업병 질병 분류에서 차지하 고 있는 비율은 거의 $90 \%$ 정도이다(Ministry of Employment and Labor, 2015). 산업재해보상보험법에 의한 업무상 질병으 로서 소음성 난청은 2014년 278명으로(Ministry of Employment and Labor, 2015) 매년 200 300건 정도가 발생하고 있다.

\section{HEALTH EFFECT OF NOISE}

사업장의 작업공정에서 발생하는 직업적 소음(occupational noise)은 음향외상과 소음성 난청 등 청각학적 영향(auditory effects)과 재해의 발생이나 작업능률의 저하 등 직접적인 각종 피해를 야기시킨다. 소음에 지속적으로 노출되지 않거나 또는 강한 소음이라도 간헐적으로 노출되는 환경소음(environmental noise)은 수면방해, 불쾌감(annoyance), 허혈성 심장질환, 그리고 아동에서 인지수행능력장애 등 비청각학적 영향(non- auditory effects)으로 건강과 일상생활에 영향을 준다. 또한 이 와같은 소음으로 인한 청력장애로 신체적, 정서적, 행동학적, 사회적 기능에 영향을 미쳐 삶의 질을 떨어뜨린다.

이러한 건강영향은 소음도와 용량반응관계를 보이며, 한밤 중의 최대 실내소음이 $50 \mathrm{~dB}(\mathrm{~A})$ 이상에서는 객관적인 수면방 해가 있고(Stansfeld \& Matheson, 2003), $70 \mathrm{~dB}$ (A) 이상(심혈 관 질환자에서는 $65 \mathrm{~dB}(\mathrm{~A})$ 이상)에서 이와 같은 건강영향이 증 가한다고 밝히고 있다(Yoshida \& Osada, 1997). 또 도로 교통 소음에 대한 도로 주변 주택 내부에서 듣는데 방해받지 않으 며 소음에 대한 불쾌감이 거의 없는 수준은 55 62 dB로 추정 하고, $1 \mathrm{~dB}$ 의 Lden이 증가할수록 $12 \%$ 의 불쾌감 호소가 증가 한다고 보고하고 있다(Klaeboe et al., 2004).

소음은 심장 및 순환기계, 내분기계, 신경계 및 소화기계 등 에 영향을 미치는 것으로 알려져 있다. 소음은 호흡, 심박동률, 표피혈류, 말초혈관의 수축, 피부온도, 떨림, 위액분비기능, 위장 관의 활동, 뇌의 생물전기적 활동 등의 생리적인 효과가 있고, 다른 한편으로는 혈중 지질, 혈중 포도당, 코르티솔, 에피네프 린, 노르에피네프린, 도파민, 성장호르몬, $\mathrm{Mg}, \mathrm{Ca}$ 농도 등의 변 화와 같은 생화학적인 효과가 있다. 소음에 대한 반응을 $\mathrm{N}$-반 응(N-response)이라 하여 (1) 말초혈관 수축으로 특징지어지는 혈관의 반응, 심장박동의 작은 변화, 대뇌 혈류의 증가, (2) 느리 고 깊은 호흡, (3) 전기적 자극에 대한 피부 저항의 변화, (4) 골격 과 근육의 긴장이 변화하고 이러한 일련의 반응에 위장관 운동 의 변화와 내분비선 자극에 의해 야기되는 소변과 혈액 안의 화학적 변화를 야기한다. 대략 $70 \mathrm{~dB}$ 크기의 소음이 $\mathrm{N}$-반응 을 유발할 수 있다.

소음의 신경세포에 대한 직접적인 영향인 기계적 손상(mechanical injury), 신경세포의 대사이상으로 인한 대사성 손상 (metabolic injury), 신경세포의 혈액순환의 손상으로 청력손실 이 온다. 코티기관의 물리적인 파괴로 나타나는 내이의 조직학 적 소견을 보면, 와우의 기저부의 청각세포와 청신경의 광범위 한 퇴행성 변화로 청력의 저하를 보이는 감각신경성 난청의 특 성을 보인다. 이 신경수용기에 도달하는 음 자극이 너무 강하 면, 일시적으로 신경의 전도성이 저하되는 신경세포의 가역적인 피로현상으로서 일시적 난청(temporary threshold shift, TTS) 이 나타나고, 반복되어 지속되면 코티기관 내의 신경수용기의 비가역적인 파괴현상으로 영구적인 소음성 난청(permanent threshold shift, PTS)이 발생한다.

소음성 난청의 청력손실은 $4,000 \mathrm{~Hz}$ 에서 가장 크며(C5-dip) 차차 $3,000,6,000,8,000,2,000,1,000$ 및 $500 \mathrm{~Hz}$ 순으로 청력 손실이 온다. $80 \mathrm{~dB}(\mathrm{~A})$ 이하 소음의 청력손실의 효과는 무시할 수 있다. 소음에 의한 청력장해는 초기에는 근로자가 자각하지 못하고 장해가 심해지면 고음역의 말을 잘 이해하지 못하다가 
나중에는 보통 회화에서도 장해를 보이게 된다.

미국산업의학회에서 기술한 소음성 난청의 주요 특성은 첫 째, 항상 내이의 모세포에 작용하는 감각신경성 난청이다. 둘 째, 거의 항상 양측성이다. 청력검사상 청각도 소견도 일반적으 로 비슷하게 양측성, 대칭적으로 나타난다. 셋째, 보통 고심도 난 청까지 이르지 않는다. 일반적으로 저주파수 한계는 약 $40 \mathrm{~dB}$ 이 며, 고주파수 한계는 약 $75 \mathrm{~dB}$ 이다. 넷째, 소음 노출이 중단되었 을 때 소음 노출의 결과로 인한 청력손실이 진행하지 않는다. 다 섯째, 과거의 소음성 난청으로 인해 소음 노출에 더 민감하게 반 응하지 않는다. 청력 역치가 증가할수록 청력손실율은 감소한다. 여섯째, 초기 저음역 $(500,1,000$ 및 2,000 Hz)에서 보다 고음역 $(3,000,4,000$ 및 $6,000 \mathrm{~Hz}$, 특히 4,000 Hz)에서 청력손실이 현 저히 심하게 나타난다(초기에는 $8,000 \mathrm{~Hz}$ 의 청력손실이 없어 노인성난청과 감별할 수 있다). 일곱째, 지속적인 소음 노출시 고음역에서의 청력손실이 보통 10 15년에 최고치에 이른다. 여 덟째, 지속적인 소음 노출이 단속적인 소음 노출보다 더 큰 장 해를 초래하는데, 단속적인 소음 노출은 휴식기간 동안 회복되 기 때문이다(Orgler et al., 1987). 소음에 대한 반응은 소음의 강도, 주파수, 소음의 복잡성, 소음의 노출시간과 기간, 개인의 감수성에 따라 다르게 나타난다.

소음은 성인에서뿐 아니라 산모의 소음 노출로 인한 태아의 청력 영향, 조기출산, 저체중아 등 태아 영향을 보고하고 있으 며, 소아 청소년기에서는 취미 및 스포츠활동의 소음 노출, 특 히 휴대용 음향기기(MP3, 카세트, CD 플레이어, 스마트폰) 사 용은 소음성 난청원으로서 $4,000 \mathrm{~Hz}$ 청력역치 증가와 관련됨 을 보여주고 있다. 청력은 소음만이 아니라 특히 연령에 의한 영향이 크며, 건강형태(음주, 흡연 등), 당뇨, 신장질환, 면역질환 (류머티스질환, 전신성 홍반성 루프스 등), 심혈관질환(고지혈 증, 동맥경화증) 등의 일반질환에서도 청력영향을 나타낸다. 이 와 같은 질환은 소음 노출군에서 소음성 난청의 위험이 더 크 게 작용한다. 그리고 작업장에서 중금속(비소, 수은, 주석, 납, 망간 등), 유기용제(톨루엔, 크실렌, 스틸렌, 트리클로로에틸렌, 헥산, 이황화탄소 등) 등의 중추신경독성물질과 압력, 진동, 라 디오파, 방사선 등의 물리적 요인도 청력에 영향을 미치며, 소 음과 더불어 상승 또는 가산적인 청력영향을 미친다. 소음성 난 청은 일반적인 광업, 제조업, 건설업과 군인 등의 고소음 노출 직종만이 아니라 공공근무 종사자(소방관, 철도, 경찰 종사자 등), 연주 음악가, 텔레마케터, 트럭운전자 등 여러 다양한 직종 에서도 문제가 되고 있다(Kim, 2013).

\section{PREVENTION OF NIHL}

세계보건기구의 환경소음 관리지침(Guidelines for commu- nity noise)에는 5 분간 연속 측정한 소음도의 평균이 거실은 35 $\mathrm{dB}$, 침실은 지속적인 소음에 대해 $30 \mathrm{~dB}(\mathrm{~A})$, 단속음에 대해서 는 $45 \mathrm{~dB}$ (LAmax), 옥외 생활지역은 지속음에 대해 $55 \mathrm{~dB}(\mathrm{~A})$ (밤에는 $45 \mathrm{~dB}(\mathrm{~A})$ ), 학교는 수업시간 동안 $35 \mathrm{~dB}(\mathrm{~A})$ 를 초과해 서는 안되고, 밤시간 동안 병원의 병실은 $30 \mathrm{~dB}(\mathrm{~A})$ 이하이어야 한다고 권고하고 있다. 소음의 허용 권장치는 비청각학적 영향 까지를 고려하여 장소마다 다르게 정하고 있다(WHO, 1999).

우리나라의 소음 관련 기본 법규로는 환경정책기본법, 소음 진동관리법, 주택건설촉진법, 항공법, 산업안전보건법에서 대상 과 목적에 따라 기준이 설정되어 있다. 우리나라의 생활소음의 규제기준은 2010년에 개정되었다. 소음진동관리법에서 공장소 음, 생활소음, 교통소음, 항공기 소음으로 구분하여 이에 대한 대책을 규정하고 있다.

우리나라는 산업장 소음에 있어서 소음발생 간격이 1 초 미 만을 유지하며 계속적으로 발생되는 소음, 즉 연속음에 대해서 는 소음 노출기준으로 $90 \mathrm{~dB}(\mathrm{~A})$ 로 규정하고 있고, 1 초 이상의 간격을 유지하면서 최대 음압수준이 $120 \mathrm{~dB}(\mathrm{~A})$ 이상의 소음, 즉 충격소음에 대해서는 소음 수준에 따른 노출횟수로 규정하 고 있다.

직업적 소음은 산업안전보건법에서 산업장 소음에 있어서의 소음발생 간격이 1 초 미만을 유지하며 계속적으로 발생되는 소 음, 즉 연속음에 대한 노출기준으로 소음강도 $90 \mathrm{~dB}(\mathrm{~A})$ 의 8시 간 노출로 규정하고 있다. 8시간 기준으로 하여 $5 \mathrm{~dB}(\mathrm{~A})$ 증가 할 때에 노출시간은 $1 / 2$ 로 감소되는 소위 $5 \mathrm{~dB}(\mathrm{~A})$ 교환율(exchange rate) 법칙이 적용되고 있다. 또 이때 소음은 $115 \mathrm{~dB}(\mathrm{~A})$ 를 초과해서는 안된다고 규정하고 있다. 그러나 최대음압수준 이 $120 \mathrm{~dB}(\mathrm{~A})$ 이상인 소음이 1초 이상의 간격으로 발생하는 충격소음은 기준을 1 일 노출회수로 규정하고 있다. 소음계로 측정한 충격소음의 강도는 1 회 노출회수가 100 일 때 최고음압 이 $140 \mathrm{~dB}(\mathrm{~A})$ 를 초과해서는 안된다고 규정하고 있다.

소음성 난청의 진단과 관리는 근로자 건강진단을 통해 이루 어지고 있다. 산업안전보건법에 의한 소음 특수건강진단은 (1) 직업력 및 노출력 조사, (2) 과거 병력 조사, (3) 자각 증상 조사, (4) 임상 진찰과 기도 순음청력검사(양쪽 귀에서 $2,000,3,000$, $4,000 \mathrm{~Hz}$ )가 1 차 검사 항목으로 포함되어 있다. 1 차 검사의 기 도 순음청력검사 중 $2,000 \mathrm{~Hz}$ 에서 $30 \mathrm{~dB} \mathrm{HL}, 3,000 \mathrm{~Hz}$ 에서 $40 \mathrm{~dB} \mathrm{HL}, 4,000 \mathrm{~Hz}$ 에서 $40 \mathrm{~dB}$ HL 이상의 청력손실을 어느 하나라도 보이는 경우에 2차 검사로 순음청력검사(양측 귀의 기도 및 골도; $500,1,000,2,000,3,000,4,000,6,000 \mathrm{~Hz}$ 순음 검사)와 중이검사(고막운동성 검사)를 한다. 특수건강진단 결 과 (1) 기도 순음청력검사 상 $4,000 \mathrm{~Hz}$ 의 고음 영역에서 $50 \mathrm{~dB}$ 이상의 청력손실이 인정되고, 삼분법(500(a), 1,000(b), 2,000(c) 에 대한 청력손실 정도로서 $(\mathrm{a}+\mathrm{b}+\mathrm{c}) / 3$ 평균 $30 \mathrm{~dB}$ 이상의 청력 
손실이 있고, (2) 직업상 소음 노출에 의한 것으로 추정되는 경 우 소음성 난청 유소견자 $\left(\mathrm{D}_{1}\right)$ 로 판정하도록 하고 있다. 건강진 단 결과 업무 수행 적합 여부를 평가하고, 건강상담, 보호구 착 용, 추적검사, 근무 중 치료, 근로시간 단축, 작업전환, 근로금지 및 제한, 직업병 확진의뢰 안내 등의 사후조치를 시행한다(KOSHA, 2015).

우리나라는 산업안전보건법 제24조 제1항2호의 규정에 의해 소음에 의한 건강장해를 예방하기 위한 필요한 조치 의무를 사 업주에게 부과하고 있는데, 제42조에 따른 소음의 작업환경 측 정 결과 소음 수준이 $90 \mathrm{~dB}(\mathrm{~A})$ 을 초과하는 사업장과 소음으로 인하여 근로자에게 건강장해가 발생한 사업장의 청력보존 프 로그램 시행을 산업안전보건기준에 관한 규칙 제 517 조에서 정 하고 있다.

산업안전보건기준에 관한 규칙 제4장 '소음 및 진동에 의한 건강장해의 예방'에서 소음 노출 평가, 노출 기준 초과에 따른 공학적 대책, 청력 보호구의 지급 및 착용, 소음의 유해성과 예 방에 관한 교육, 정기적 청력검사, 기록·관리 등이 포함된 소음 성 난청을 예방 관리하기 위한 종합적인 계획으로서 청력보존 프로그램 시행을 규정하고 있다.

사업주는 강렬한 소음작업 또는 충격소음작업 장소에 대하 여는 기계·기구 등의 대체, 시설의 밀폐·흡음 또는 격리 등 소 음 감소를 위한 조치를 하여야 하며(제513조), 소음작업, 강렬 한 소음작업 또는 충격소음 작업자에게 (1) 해당 작업 장소의 소음 수준, (2) 인체에 미치는 영향 및 증상, (3) 보호구의 선정 및 착용 방법, (4) 그 밖에 소음건강장해 방지에 필요한 사항을 알려야 하며(제514조), 소음으로 인하여 건강장해자가 발생하였 거나 발생할 우려가 있는 경우에는 소음성 난청 발생 원인조사, 청력손실 감소 및 재발 방지 대책 마련, 작업전환 조치 등을 하 여야 한다(제 515 조). 건강장해자는 산업재해보상보험법에 의한 업무상 질병 인정자로, 우려가 있는 경우는 근로자 건강진단 결 과 질병 유소견자(D1)가 발생한 경우로 해석한다. 사업주는 근 로자에게 개인 전용의 청력 보호구를 지급.착용토록 하고, 근 로자는 지급된 보호구를 사업주의 지시에 따라 착용하여야 한 다(제516조).

청력보존 프로그램은 소음 측정, 공학적 소음 제어와 행정적 관리, 청력 보호구 착용, 청력검사 및 의학적 판정, 보건 교육 및 훈련, 기록보관 및 프로그램 효과 평가 등 7개의 구성 요소 로 되어 있다. 소음 측정은 과노출되는 근로자와 과노출에 기여 하는 기계, 즉 소음 발생원을 파악하기 위해 필요하며, 공학적 대책은 장기간 소음 노출과 관련한 가장 근본적인 대책이라고 볼 수 있다. 소음 문제는 발생원, 경로, 수용자(근로자)와 같은 세 가지 요소에 의해 구분되며, 발생원을 조절하는 것이 가장 만족스러운 방법이다. 청력 보호구 착용은 소음성 난청을 예방
하는 또 다른 중요한 방법이다. 청력검사 자체는 실제적으로 근 로자를 보호하지는 못하지만 청력보존 프로그램이 효과적으로 진행 중인지를 알려 주는 유일한 방법이다. 근로자가 청력보존 프로그램을 제대로 교육받고 잘 이해한다면 이 프로그램의 성 공률은 매우 클 것이다. 그리고 이 프로그램의 마지막 요소로 서 기록 보존을 들 수 있는데, 이는 프로그램이 성공적인 기능 을 하는 데 필수적이다.

현재 청력보존 프로그램과 관련한 산업안전보건공단의 지침 으로 청력보존 프로그램의 수립·시행 지침(KOSHA GUIDE, $\mathrm{H}-61-2012)$, 청력보존 프로그램의 시행을 위한 청력평가지침 (KOSHA GUIDE, H-55-2012), 청력보존 프로그램의 효과 평 가지침(KOSHA GUIDE, H-7-2012), 청력평가와 관련한 청력 검사로서 순음청력검사에 관한 지침(KOSHA GUIDE, H-562014)이 있다.

중심 단어 : 소음·소음성 난청·예방·한국.

\section{REFERENCES}

Occupational Safety and Health Research Institute, KOSHA. (2015). Workers' Health Examination Practices.

Jang, J. K. \& Chung, K. J. (2007). A study on the management of noise in work-environments. Ulsan, Korea: Occupational Safety and Health Research Institute, KOSHA.

Kim, K. S. (2013). Noise and Hearing. Paju, Korea: Korean Studies Information.

Kim, K. S., Kim, E. A., Kim, K. H., \& Kim, D. S. (2010). Correlation between hazardous factors and diseases of special health examination subjects: based on results from measurement of noise exposure and special health examination. Ulsan, Korea: Occupational Safety and Health Research Institute, KOSHA.

Klæboe, R., Amundsen, A. H., Fyhri, A., \& Solberg, S. (2004). Road traffic noise-the relationship between noise exposure and noise annoyance in Norway. Applied Acoustics, 65, 893-912.

Ministry of Employment and Labor. (2015). 2014 Industrial Accident Anal$y$ sis.

Ministry of Employment and Labor. (2015). 2014 Workers Health Checkups Results.

Nelson, D. I., Nelson, R. Y., Concha-Barrientos, M., \& Fingerhut, M. (2005). The global burden of occupational noise-induced hearing loss. American Journal of Industrial Medicine, 48(6), 446-458.

Niskar, A. S., Kieszak, S. M., Holmes, A. E., Esteban, E., Rubin, C., \& Brody, D.J. (2001). Estimated prevalence of noise-induced hearing threshold shifts among children 6 to 19 years of age: the Third National Health and Nutrition Examination Survey, 1988-1994, United States. Pediatrics, 108(1), 40-43.

Orgler, G. K., Brownson, P. J., Brubaker, W. W., Crane, D. J., Glorig, A., Hatfield, T.R., et al. (1987). American Occupational Medicine Association Noise and Hearing Conservation Committee Guidelines for the Conduct of an Occupational Hearing Conservation Program. Journal of Occupational Medicine, 29, 981-982.

Stansfeld, S. A. \& Matheson, M. P. (2003). Noise pollution: non-auditory effects on health. British Medical Bulletin, 68, 243-257.

WHO. (1999). Guidelines for community noise. London: World Health Organization.

Yoshida, T. \& Osada, Y. (1997). Effects of road traffic noise on inhabitant of Tokyo. Journal of Sound and Vibration, 205(4), 517-522. 